Thorn, Green, Dalerum, Bateman, \& Scott

\title{
What Drives Human-Carnivore Conflict in the North West Province of South
}

\section{Africa?}

\section{Michelle Thorn*a, b ${ }^{\text {, Matthew Green }}{ }^{\mathrm{b}}$ Fredrik Dalerum ${ }^{\mathrm{b}, \mathrm{c}}$, Philip W. Bateman ${ }^{\text {d,e }}$,}

Dawn M. Scott ${ }^{\mathrm{a}}$

${ }^{\mathrm{a}}$ University of Brighton, Biology Division, Huxley Building, Lewes Road, Moulsecoomb, Brighton, BN2 4GJ, UK. E mail: Dawn.Scott@Brighton.ac.uk

${ }^{b}$ Mammal Research Institute, Department of Zoology and Entomology, University of

Pretoria, 0002, Pretoria, South Africa. E mail: Fredrik.dalerum@zoology.up.ac.za

${ }^{c}$ Centre for Wildlife Management, Hatfield Experimental Farm, University of Pretoria, 0002, Pretoria, South Africa.

${ }^{\mathrm{d}}$ School of Veterinary and Biomedical Sciences, Murdoch University, Murdoch WA 6150, Australia.

e Department of Zoology and Entomology, University of Pretoria, 0002, Pretoria, South Africa. E mail: Pwbateman@zoology.up.ac.za

Key Words: Game; lethal control; livestock; perceptions; predation; questionnaire interview.

*To whom correspondence should be addressed. Email: Thorn_Green@Hotmail.com 
Thorn, Green, Dalerum, Bateman, \& Scott

\begin{abstract}
Alleviating human-carnivore conflict is central to large carnivore conservation and is often of economic importance where people co-exist with carnivores. However, effective conflict mitigation requires knowledge of underlying human and environmental drivers that is largely absent in South Africa. From 2006 to 2008, we interviewed land owners in the North West Province of South Africa to quantify; 1) human-carnivore conflict characteristics and; 2) determinants of perceived predation levels and retaliatory persecution of carnivores. Carnivores reportedly killed 3755 animals i.e. $2.77 \%$ of total game and livestock holdings. Reported financial losses were unevenly distributed among individuals, but generally not of sufficient magnitude to constitute a serious economic threat. Dense cover, increasing distance from protected areas and land use were the most influential determinants of perceived predation levels. Cultural group was by far the most influential determinant of carnivore persecution. Black-backed jackals and caracals were most often implicated in predation and most frequently killed by interviewees.

Conflict in the North West Province appears to be driven more by social and environmental factors than by economic losses. Therefore, mitigation efforts that foster positive attitudes to carnivores may have greater impact than activities intended to reduce livestock predation losses. More generally, our combination of socio-economic interviews and information theoretic analysis demonstrates a simple and effective method for identifying the key determinants of complex human-wildlife conflicts.
\end{abstract}


Thorn, Green, Dalerum, Bateman, \& Scott

\section{Introduction}

Human persecution is a world-wide threat to large carnivores (Treves and Karanth, 2003) (defined here as $>10 \mathrm{~kg}$ body weight), contributing to the global decline of many species (IUCN, 2009). Although persecution may stem from carnivore attacks on people, more often it arises from competition between people and carnivores over limited resources. Such resources typically include space and animals (e.g. livestock or game species) that have economic, nutritional or recreational value (Graham et al., 2005; Inskip and Zimmermann, 2009). Conflict of this sort is increasingly common due to human population growth and concomitant rises in human appropriation of natural resources (Graham et al., 2005; Treves and Karanth, 2003).

Large carnivores are prone to conflict with people. They typically have large home ranges that increasingly overlap with human-occupied areas, due to widespread anthropogenic destruction and fragmentation of carnivore habitat (Treves and Karanth, 2003). They also have high dietary protein requirements (Treves and Karanth, 2003) and carnivores inhabiting agricultural landscapes often prey upon game or livestock (Inskip and Zimmermann, 2009), particularly if human activities have depleted wild prey (Graham et al., 2005; Gusset et al., 2009). Carnivores are also susceptible to a range of infectious diseases (Murray et al., 1999) that can be transmitted to game and livestock. Consequently, they are widely perceived as inimical to animal farming and are frequently killed in an effort to prevent or reduce losses (Treves and Karanth, 2003). Alleviating human-carnivore conflict is therefore pivotal to conserving declining large carnivore 
Thorn, Green, Dalerum, Bateman, \& Scott

populations, especially where animal production is a prevalent land use (Graham et al., 2005; Inskip and Zimmermann, 2009; Treves and Karanth, 2003).

However, livestock predation can jeopardise farming livelihoods and agricultural production (Graham et al., 2005; Treves and Karanth, 2003; Woodroffe et al., 2007). For example wolves (Canis lupus), red foxes (Vulpes vulpes), lynx (Lynx lynx) and coyotes (Canis latrans) prey upon sheep in North America and Europe (Baker and Harris, 2006; Prugh et al., 2009; Treves and Karanth, 2003) and leopards (Panthera pardus) kill livestock in Asia (Dar et al., 2009). In subsistence farming areas predation may also hinder rural development and threaten food security (Graham et al., 2005; Treves and Karanth, 2003; Woodroffe et al., 2007). Carnivore conservation approaches that ignore such issues are unlikely to be supported by local people and cannot practically be enforced in remote areas (Lindsey et al., 2009). They may also provoke hostility toward conservation initiatives in general (Dar et al., 2009). Sustainable conflict mitigation strategies must therefore balance human interests with biodiversity conservation objectives. This demands a clear understanding of the nature and underlying human and environmental drivers of conflict.

In South Africa, land used for domestic livestock farming and game ranching accounts for an estimated $68.6 \%\left(839281 \mathrm{~km}^{2}\right)$ of total land area (Department of Agriculture Forestry and Fisheries, 2010). In these areas, human-wildlife conflict (including humancarnivore conflict) is so frequent that legislation regulating lethal control of 'damage causing' species is currently in preparation (Molewa, 2010). The most recent national 
Thorn, Green, Dalerum, Bateman, \& Scott

conservation assessment for mammals lists human persecution as the main threat to carnivores outside protected areas (Friedmann and Daly, 2004). Despite an apparent need for effective mitigation strategies, quantitative scientific data concerning humancarnivore conflict are largely absent. To address this deficit, we interviewed game and livestock farmers in the North West Province of South Africa. The province occupies $9.5 \%$ of South Africa's surface area and being a predominantly rural area, agriculture (including animal production) is the second largest contributor to provincial GDP (Statistics South Africa, 2008; Tladi et al., 2002). We sought to establish current predation levels by and perceived culpability of carnivore species; predation costs compared with other common sources of financial loss; and use of lethal and non-lethal anti-predation measures. Quantifying such characteristics is essential for the development of carnivore conservation strategies that effectively address the causes of persecution-related threats. With this in mind, we also investigated the influence of possible environmental and anthropogenic determinants of perceived predation levels and retaliatory persecution of carnivores. Our analysis reveals the relative importance and effect of these variables and suggests priorities for future conflict mitigation strategies.

\section{Materials and methods}

\subsection{Study Area}

At the time of the study the North West Province of South Africa spanned $116320 \mathrm{~km}^{2}$ (Figure 1). 
Figure 1. Questionnaire interview locations $(n=99)$ in relation to main land cover classes in the North West Province. The shaded area on the inset indicates the position of the study area in South Africa.

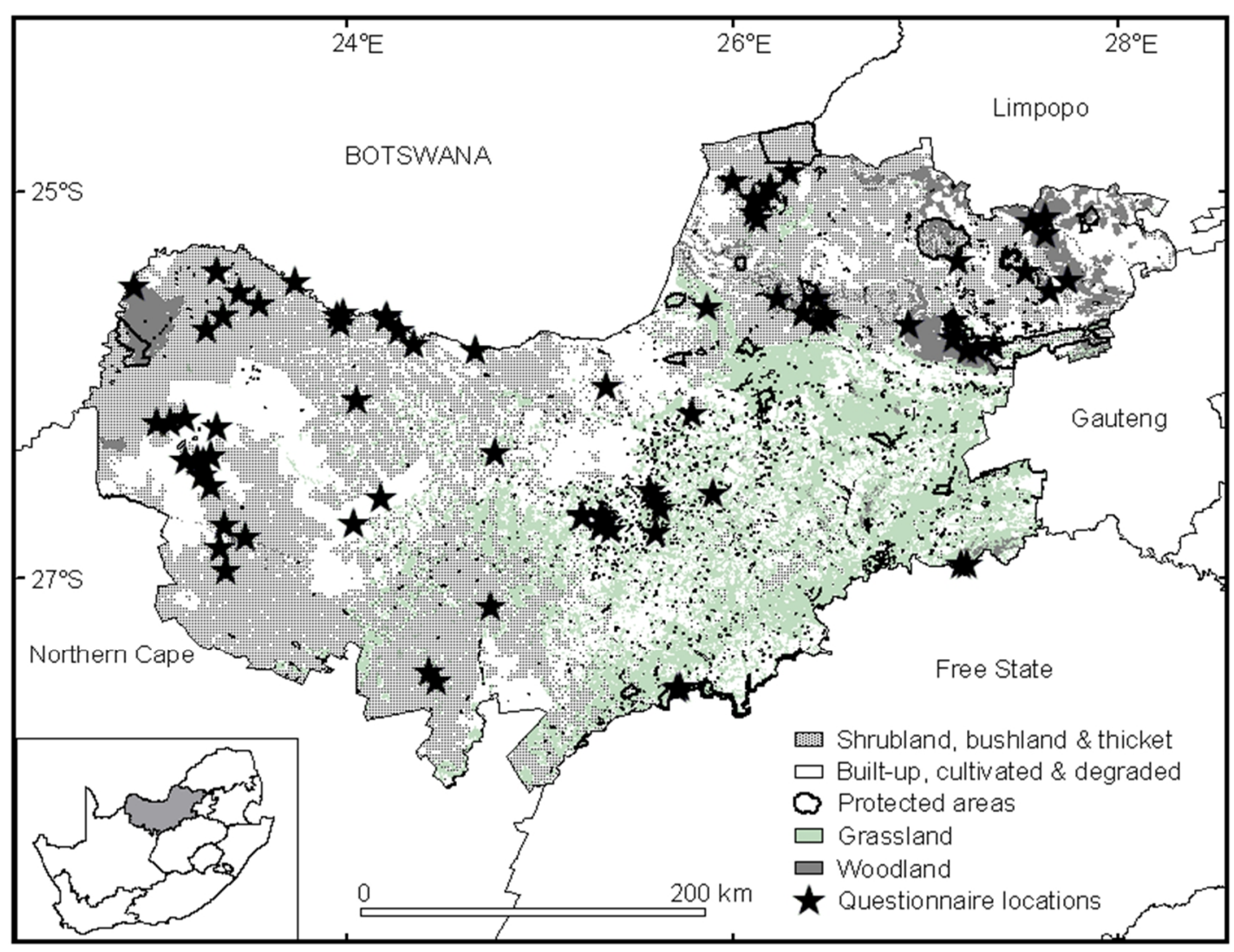

The western half of the province is semi-arid and characterised by xerophytic vegetation (De Villiers and Mangold, 2002). Open grassland and savannah predominate in central areas, whereas eastern areas have a temperate climate, the highest rainfall and greatest diversity of vegetation types. Annual rainfall ranges from 200-650 mm, with a wet season from October to March. Maximum mean daily temperatures reach $32^{\circ} \mathrm{C}$ in January and minimum mean daily temperatures drop to $1^{\circ} \mathrm{C}$ in July. 
Thorn, Green, Dalerum, Bateman, \& Scott

Protected areas occupy $2.4 \%$ of the province, whereas $54 \%$ is used for grazing, $30 \%$ is used for crop farming, $11 \%$ is used for human settlements and $2.6 \%$ is used for forestry and mining (Tladi et al., 2002). Revenue from domestic livestock farming comprises mainly meat, dairy and wool sales from cattle and small-stock (pigs, sheep and goats) (Department of Agriculture Forestry and Fisheries, 2010). However, according to Bothma (2005) game farming (mainly non-domesticated ungulates) is increasingly prevalent because it is often more profitable than cattle or small-stock farming, especially in arid areas. Game farming revenue stems mainly from hunting, sale of live animals, stud breeding and tourism. The development of the game farming industry is not well documented, but in the 1960s there were just 10 game farms compared with $>14000$ now, and the land area used for game farming is thought to have increased by $3-5000 \mathrm{~km}^{2}$ annually in the late $1990 \mathrm{~s}$ and early 2000s (Bothma, 2005). In recent years, breeding of rare colour morphs and sub-species has become increasingly prevalent as sale prices for such animals have escalated. For example, the average sale price at auction for a standard impala (Aepyceros melampus) male in ... was ZAR, compared with ZAR for a black colour morph of the same species.

Several large carnivore species that may prey upon game and livestock are resident in agricultural areas of the province. Caracals (Caracal caracal) and black-backed jackals (Canis mesomelas; hereafter referred to as jackals) are widespread, abundant and classified by the IUCN as Least Concern (Friedmann and Daly, 2004). Leopards are globally classified as Near Threatened, but nationally classified as Least Concern (Friedmann and Daly, 2004), but distribution patterns in the North West Province suggest possible range contraction (Thorn et al., 2011b). Most free-ranging leopards, cheetahs (Acinonyx jubatus; classified as Vulnerable) and brown hyaenas (Hyaena brunnea; 
Thorn, Green, Dalerum, Bateman, \& Scott

classified as Near Threatened) are found outside protected areas (Marnewick et al., 2007a; Mills and Hofer, 1998). Persecution in farmlands is therefore considered a serious threat to those species (Friedmann and Daly, 2004). Apex predators such as African wild dogs (Lycaon pictus), spotted hyaenas (Crocuta crocuta) and lions (Panthera leo) also occur in our study area, but are resident only inside fenced protected areas.

\subsection{Interview Methods and Questionnaire Design}

To obtain information on human-carnivore conflict, we interviewed farmers throughout the North West Province between October 2006 and September 2008. Each interview typically took 40 minutes to complete and was administered in person, either by M.T in English or by Setswana speakers (a member of the Department of Nature Conservation and a volunteer). We selected subjects based on a sampling frame consisting of a grid of $415 \mathrm{~km}^{2}$ cells overlaid on the study area (see Thorn et al., 2011a for detailed explanation of the sampling frame). We conducted the majority of interviews in 25 randomly selected cells but recruited additional participants opportunistically at livestock auctions and farmers' meetings to increase overall sample size. We based our interviews on a semi-structured questionnaire (available from M.T.) that was piloted prior to use. The questionnaire contained four sections, three of which are relevant here.

The first section focussed on information relating to participants and their farms.

Questions included age, length of tenure at the farm and cultural group (based on first language e.g. Afrikaans, English or Setswana). The questions also included farm size and the estimated extent of grassland and crop areas (open cover habitats) compared with 
Thorn, Green, Dalerum, Bateman, \& Scott

scrub and woodland areas (dense cover habitats). From this we determined the predominant level of cover available to carnivores. We plotted the GPS location of each interview in ArcView v3.3, and extracted the distance between the interview location and the boundary of the closest protected area.

The second section focussed on carnivore presence and predator-prey interactions. We recorded the species and estimated number of game and livestock at each farm. Respondents gave details of animals (species, number and current sale price) they thought had been preyed upon by carnivores in the year prior to the interview. They also indicated which carnivore species they thought responsible, and why.

Section three focused on the use of anti-predation measures including protective enclosures, livestock guards and lethal control of carnivores (use/non-use as well as species and number of carnivores killed). We also asked respondents to rank common sources of economic loss (fire, poaching, livestock disease and drought) in order of perceived cost.

\subsection{Analysis}

We pooled data from random and opportunistic samples and from different observers after confirming that there were no significant differences with regard to the response and predictor variables used in regression analysis (Table 1). We then summarised variables relating to conflict characteristics using standard descriptive statistics. We calculated 
Table 1. Predictor variables and their anticipated effect on response variables that indicate human-

carnivore conflict.

Predictor variable $\quad$ Predicted effect

Response variable: no. of game and livestock reportedly killed by carnivores at each farm:

Anti-predation measures

(lethal control, non-lethal methods, both or neither )

Land use (livestock, game or mixed farming)

Total prey density (individuals $/ \mathrm{km}^{2}$ )

Distance to nearest protected area (km)

Cover (open, dense, or equal proportions of open and dense cover i.e. heterogeneous)
Indiscriminate lethal control is unlikely to reduce predation because it does not necessarily remove 'problem' carnivores that repeatedly prey upon livestock ${ }^{1}$ and often has little long-term effect on large carnivore density ${ }^{2,3}$. Non-lethal measures such as guarding livestock or confining them to protective enclosures during periods when they are most vulnerable to predators been shown to reduce predation losses in a number of studies world-wide ${ }^{4,5}$.

We would expect intensive management and associated anti-predation measures on livestock farms to result in lower predation levels compared with game or mixed farms.

We would expect a positive relationship between stocking densities and the frequency with which carnivores encounter potential prey, resulting in higher levels of predation in sites with high prey density.

Game and livestock losses increase with proximity to protected areas harbouring apex carnivores ${ }^{4}$. Meso-predator release in farmland can cause the opposite pattern ${ }^{4}$. As most apex predators in our study area are confined to fenced reserves, we expect the latter.

Dense vegetation increases the cover available to carnivores, which has been shown to increase felid predation on livestock ${ }^{5,6}$.

Response variable: use (1) or non-use (0) of lethal control:

Predation losses (ZAR)

High financial losses are expected to increase the use of lethal control ${ }^{2}$.

Land use (livestock, game or mixed farming)

Predation of intensively managed livestock is easier to detect and quantify than loss of extensively managed game. Furthermore, livestock farming is often less profitable than game ranching ${ }^{7}$, increasing the financial impact of predation losses. We therefore suspect that greater awareness of losses coupled with lower profitability may provoke increased use of lethal control among livestock farmers.

Farmer age (years) Previous studies found that younger farmers tend to be more tolerant of carnivores ${ }^{8}$ and should, therefore, be less likely to use lethal control.

Farmer cultural group (Afrikaans, We expect tolerance toward large carnivores and thus, prevalence of lethal control Setswana or English) to differ among cultural groups ${ }^{8}$.

Sources: ${ }^{1}$ (Inskip and Zimmermann, 2009), ${ }^{2}$ (Woodroffe and Frank, 2005), ${ }^{3}$ (Prugh et al., 2009), ${ }^{4}$ (Gusset et al., 2009), ${ }^{5}$ (Woodroffe et al., 2007), ${ }^{6}$ (Michalski et al., 2006), ${ }^{7}$ (Bothma, 2005), ${ }^{8}$ (Lindsey et al., 2005).

destruction rates for each carnivore species (number exterminated/total land area of farms

surveyed). Destruction rates for species with restricted ranges (cheetahs, leopards and

brown hyaenas) were adjusted by excluding farms that did not fall within the species

range, as estimated by local experts (Thorn et al., 2011b). To give a coarse outline of the

wider impact of current levels of carnivore removals, we extrapolated our destruction

rates to the grazing areas of the North West Province that fall within species' ranges. 
Thorn, Green, Dalerum, Bateman, \& Scott

Prey preference was assessed using Jacobs' index (Jacobs, 1974):

$$
D=\frac{r-p}{r+p-2 r p}
$$

The index standardises the relationship between relative abundance ( $p$; species abundance as a proportion of all stock holdings) and relative predation ( $r$; number of individuals predated by species, as a proportion of all individuals predated). This produces values from -1 to +1 , signifying maximum prey avoidance and preference respectively. We also performed a chi square test to confirm the results from the index, interpreting the expected frequency of individuals predated versus the observed frequency of individuals predated as an indication of preference or avoidance.

To evaluate the effect of potential determinants of conflict, we fitted two sets of generalised linear regression models. The first set evaluated the effect of a range of farmspecific and environmental predictors (Table 1) on the number of game and livestock reportedly preyed upon at each farm. In these models, we used a negative binomial error distribution to account for overdispersion and a log link function. Secondly, we evaluated the effects of plausible social, economic and environmental predictors (Table 1) on the probability of retaliatory persecution of carnivores. In these models, we used the binary response variable use or non-use of lethal control, a binomial error distribution and a logit link function. For both sets of models, we performed a Spearman's Rank correlation matrix prior to analysis to confirm that none of the predictor variables were intercorrelated using Spearman's rho $\left(\mathrm{r}_{\mathrm{s}}\right)>0.7$ as a criterion for exclusion (Kolowski and Holekamp, 2006). We identified and removed extreme outliers with Cook's distance $>1$ (Cook and Weisberg, 1982). 
Thorn, Green, Dalerum, Bateman, \& Scott

For each response variable, the set of candidate models contained all additive combinations of predictors as well as all two-way interactions. Within each of the two model sets, we ranked models in order of parsimony using Akaike's Information Criterion adjusted for small sample size $\left(\mathrm{AIC}_{\mathrm{c}}\right)$ (Burnham and Anderson, 2002). Models within $7 \Delta \mathrm{AIC}_{\mathrm{c}}$ units of the model with the lowest $\mathrm{AIC}_{\mathrm{c}}\left(\Delta \mathrm{AIC}_{\mathrm{c}} \leq 7\right)$ were considered to have sufficient relative support to be included in the final set of explanatory models (Burnham and Anderson, 2002; Burnham et al., 2011). We excluded models that were simply a more complicated version (i.e. additional parameters) of a nested model with lower $\mathrm{AIC}_{\mathrm{c}}$, to reduce selection of overly complex models (Burnham and Anderson, 2002). We then used Akaike model weight to determine the relative probability of each model being the most parsimonious in the candidate model set, and summed weights to evaluate the relative importance of determinants (Burnham and Anderson, 2002). We predicted effect sizes from regression coefficients $(\beta)$, and where several additive models received similar support (i.e. $\Delta \mathrm{AIC}_{\mathrm{c}} \leq 7$ ), we averaged $\beta$ values from those models.

Analysis was conducted using SPSS v17 (SPSS Inc., Chicago, USA). Financial values throughout are given in South African Rand (ZAR 1 = GBP 0.09= USD 0.15).

\section{Results}

We conducted 99 interviews (Figure 1), 64\% of which were in randomly selected survey cells. There were no refusals to participate. 
Thorn, Green, Dalerum, Bateman, \& Scott

\subsection{Characteristics of the sample}

Sixty nine percent of interviewees were $>40$ years old, $67 \%$ had $>10$ years tenure and almost all were resident at their farm. Twenty three percent were Setswana-speaking, $63 \%$ were Afrikaans-, or German and Afrikaans-speaking, and 10\% were Englishspeaking. The best available information (Tladi et al., 2002) suggests that those proportions approximate the proportion of land owned or managed by Setswana speakers in the areas surveyed. The same is true for non-Setswana speakers collectively. Furthermore, farmers of Afrikaans and German origin are a culturally homogenous group (Marker et al., 2003). We therefore consider the sample to be approximately representative of the population of farmers in the study area. There were no significant differences in the age structure of the cultural groups $\left(\chi_{4}^{2}=3.735, P=0.443\right)$.

The size of properties where interviews were conducted ranged from 1.64 to $960 \mathrm{~km}^{2}$ $\left(25^{\text {th }}\right.$ percentile $9 \mathrm{~km}^{2}$, median $19.95 \mathrm{~km}^{2}, 75^{\text {th }}$ percentile $\left.45.71 \mathrm{~km}^{2}\right)$. The total land area of the properties was $4134 \mathrm{~km}^{2}$, representing $7 \%$ of agricultural land in the province. The majority of the 99 interviewees $(73 \%)$ owned $<1000$ livestock $\left(25^{\text {th }}\right.$ percentile 212 , median $496,75^{\text {th }}$ percentile 1135 ). Most interviewees used their land for more than one type of agricultural production. Thirty five percent farmed mainly livestock, $23 \%$ farmed mainly game, and $38 \%$ were mixed farms that used approximately equal proportions of land for livestock and game, or livestock and crops. 
Thorn, Green, Dalerum, Bateman, \& Scott

Table 2. Number of individuals, by species, reportedly predated in the year preceding interviews $(n=99)$.

Relative predation and abundance are the proportion that each species comprised of all individuals predated and all stock holdings respectively. Jacob's Index expresses prey preference (positive values, maximum +1 ) or avoidance (negative values, minimum -1). E $X^{2}$ is the expected number of individuals predated, according to a chi square test of association $\left(\chi_{20}^{2}=5959.056, P<0.001\right)$ between number predated and species abundance.

\begin{tabular}{lrccrr}
\hline Species & $\begin{array}{r}\text { Number } \\
\text { predated }\end{array}$ & $\begin{array}{c}\text { Relative } \\
\text { predation }\end{array}$ & $\begin{array}{c}\text { Relative } \\
\text { abundance }\end{array}$ & $\begin{array}{r}\text { Jacobs' } \\
\text { index }\end{array}$ & $\mathrm{E} X^{2}$ \\
\hline Goat (Capra hircus) & 1412 & 0.3740 & 0.1255 & 0.61 & 528 \\
Sheep (Ovis aries) & 1055 & 0.2795 & 0.1644 & 0.33 & 668 \\
Springbok (Antidorcas marsupialis) & 357 & 0.0946 & 0.0195 & 0.68 & 86 \\
Cattle (Bos spp.) & 334 & 0.0885 & 0.4111 & -0.76 & 1606 \\
Ostrich (Struthio camelus) & 196 & 0.0519 & 0.0034 & 0.88 & 19 \\
Impala (Aepyceros melampus) & 155 & 0.0411 & 0.0447 & -0.04 & 178 \\
Blesbok (Damaliscus dorcas) & 71 & 0.0188 & 0.0152 & 0.11 & 61 \\
Horse (Equus caballus) & 52 & 0.0138 & 0.0044 & 0.52 & 18 \\
Steenbok (Raphicerus campestris) & 43 & 0.0114 & 0.0311 & -0.47 & 122 \\
Common duiker (Sylvicapra grimmia) & 40 & 0.0106 & 0.0302 & -0.49 & 119 \\
Mountain reedbuck (Redunca fulvorufula) & 25 & 0.0066 & 0.0016 & 0.61 & 7 \\
Poultry (various avian spp.) & 12 & 0.0032 & 0.0021 & 0.21 & 9 \\
Roan (Hippotragus equinus) & 6 & 0.0016 & 0.0003 & 0.68 & 1 \\
Sable (Hippotragus niger) & 4 & 0.0011 & 0.0026 & -0.42 & 10 \\
Kudu (Tragelaphus strepsiceros) & 3 & 0.0008 & 0.0279 & -0.95 & 109 \\
Gemsbok (Oryx gazella) & 3 & 0.0008 & 0.0136 & -0.89 & 53 \\
Blue Wildebeest (Connochaetes taurinus) & 2 & 0.0005 & 0.0129 & -0.92 & 50 \\
Nyala (Tragelaphus angasii) & 2 & 0.0005 & 0.0018 & -0.55 & 7 \\
Warthog (Phacochoerus africanus) & 1 & 0.0003 & 0.0221 & -0.98 & 86 \\
Bushbuck (Tragelaphus scriptus) & 1 & 0.0003 & 0.0012 & -0.63 & 5 \\
Zebra (Equus quagga) & 1 & 0.0003 & 0.0088 & -0.94 & 34 \\
\hline & & & & &
\end{tabular}

\subsection{Human-carnivore conflict characteristics}

\subsubsection{Number and species predated}

The total number of game and livestock owned by respondents was 136337 , of which $2.77 \%$ (3755) were reportedly preyed upon by carnivores (Table 2, Figure $2 \mathrm{a} \& 2 \mathrm{~b}$ ). The proportion of stock holdings reportedly predated per farm was Poisson distributed with a 
Thorn, Green, Dalerum, Bateman, \& Scott

median of $1.23 \%\left(25^{\text {th }}\right.$ percentile $=0 \%, 75^{\text {th }}$ percentile $\left.=5.75 \%\right)$. Extremely high losses (10 - 51\% of stock holdings) were reported by $17 \%$ of interviewees, with one extreme outlier ( $89 \%$ of stock holdings). Many land owners cited lack of game species population growth as indirect evidence of predation, but as such losses were unquantifiable and could be caused by factors other than carnivore predation, they were not recorded.

Of the 76 people who declared losses due to predation, 57\% said that most of the game and livestock animals preyed upon (hereafter referred to as prey) were $<12$ months old. The perceived number of individuals predated was significantly associated with species abundance $\left(\chi_{20}^{2}=5959.056, P<0.001\right)$. Four of the six most preferred prey species (based on Jacobs' index values) were game species with adult female body weight between 23 and $70 \mathrm{~kg}$ (see Hayward et al., 2006a; Hayward et al., 2006b and references cited therein for body weights). However, 130 of 196 predated ostriches were taken at one breeding centre and were sub-adults whose weight would be at the lower end of that range. Horses were predated only in tribal areas, and all of the predated roan antelope were from one ranch, implying anomalous localised conditions rather than a general preference. Cattle were avoided, whereas smaller livestock species (goats and sheep) were preferred. The other seven species avoided were game, most had adult female body weight $\geq 135 \mathrm{~kg}$, and all had low relative abundance.

\subsubsection{Financial losses in relation to farming livelihoods and the provincial economy}

The total value of reported annual predation losses was ZAR $4334454\left(25^{\text {th }}\right.$ percentile $=$ ZAR 0, median $=$ ZAR 6300, $75^{\text {th }}$ percentile $=$ ZAR 29 001). High losses $($ ZAR 106200 
Figure 2. The reported number of animals per farm $(n=95)$ that were killed by carnivores (median, 25 and $75 \%$ quartiles, maximum, minimum and outliers [*]), by a) distance to the nearest protected area (DTPA) \& land use and b) DTPA \& cover. Followed by model predictions (see Table $4, \operatorname{Exp}(\hat{\beta}))$ of the effect that c) DTPA \& land use and d) DTPA \& cover have on the number of animals predated by carnivores.

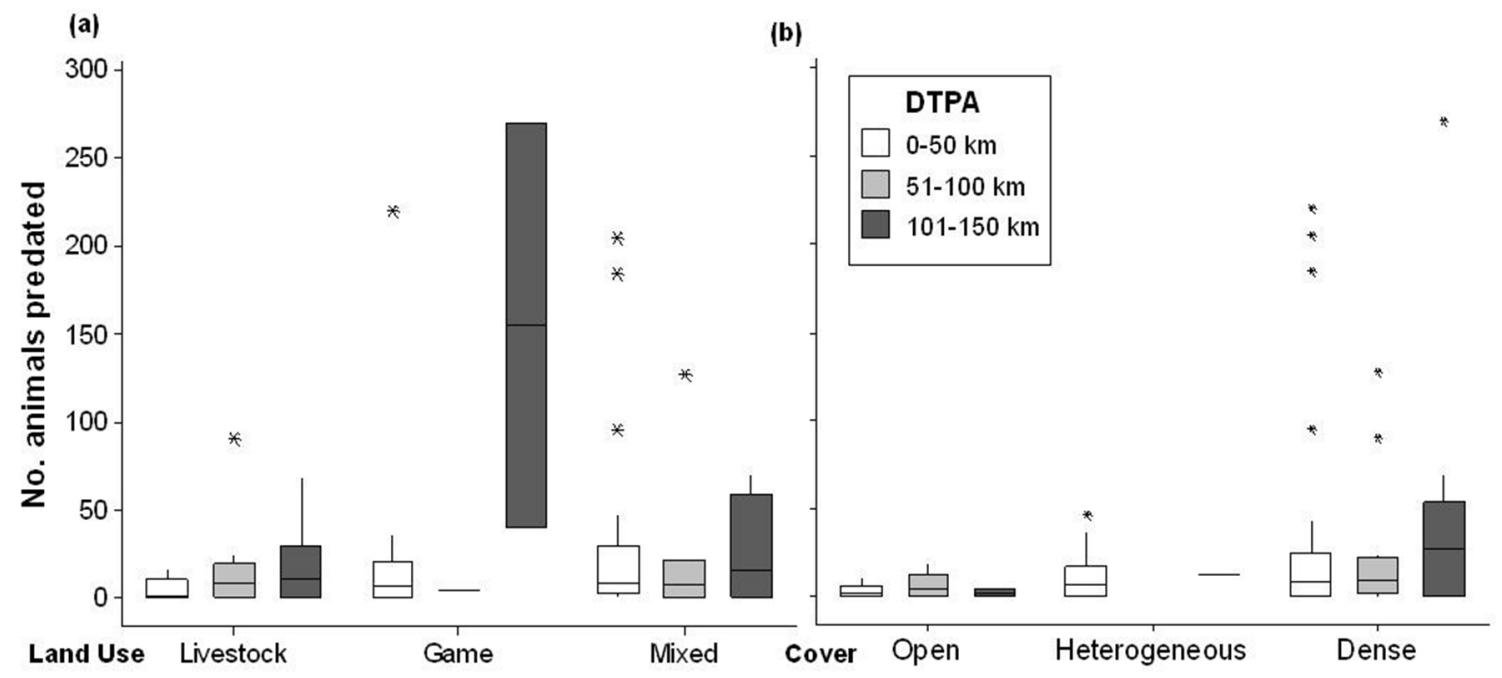

(c)

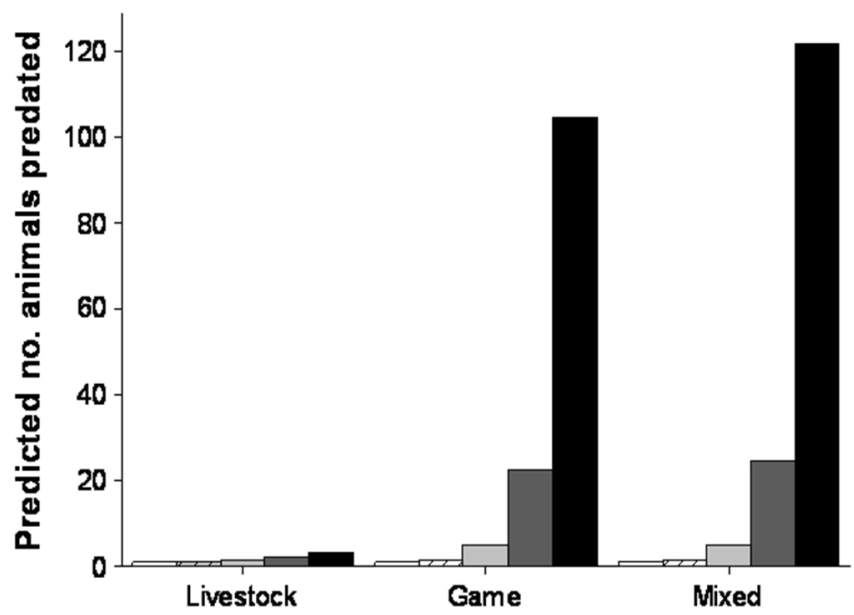

(d)

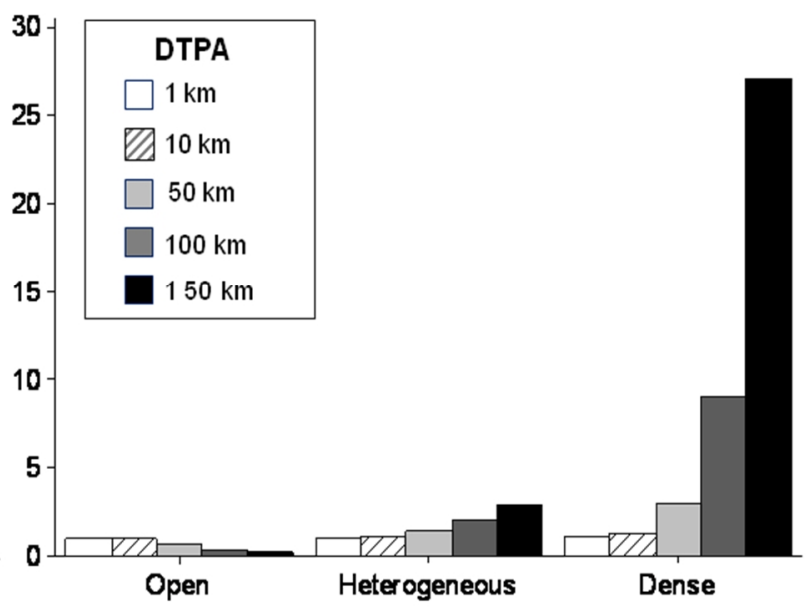

- 1393 650) were reported by 10 interviewees. The largest loss (ZAR 1393 650)

reflected predation of 10 high-value antelope, rather than excessively large numbers of animals preyed upon. 
Thorn, Green, Dalerum, Bateman, \& Scott

To assess whether reported financial losses were congruent with market values, we compared sale prices estimated by interviewees with independent data such as sale prices at game and livestock auctions in 2008. Although we cannot corroborate the perceived number of animals lost, we found that in general our interviewees did not over-estimate predated game and livestock values.

Of 97 interviewees who answered the question, $32 \%$ considered poaching the most costly source of economic loss, followed by drought (30\%), predation (19\%), fire (11\%) and game or livestock diseases $(8 \%)$.

Cumulative reported annual financial losses at the median totalled ZAR 52 654. Dividing those losses by the land area of the farms where they occurred gives a ZAR $0.222 /$ ha rate of loss. Cumulative annual losses at the $75^{\text {th }}$ percentile (ZAR 406 929) equate to ZAR $1.225 /$ ha. Extrapolating the $75^{\text {th }}$ percentile rate of loss across all grazing land in the province $\left(62812.8 \mathrm{~km}^{2}\right)$ gives estimated provincial losses of $\leq$ ZAR 7697 162/year. There is a shortage of published data regarding game and livestock farming profitability in South Africa (Bothma, 2005). However, estimated gross income from animal-related agriculture in the North West Province in 2007 was ZAR 5052478000 (Statistics South Africa, 2007). Estimated net operating profit for game farms in grassland areas is 52$68 \%$ of gross income, versus $21-33 \%$ for cattle farms and $41 \%$ for sheep farms (ABSA, 2003) Assuming a similar income to profit ratio in the North West Province, our provincial predation losses therefore equate to $0.22-0.29 \%$ of annual net operating profit for game farms, compared with $0.46-0.73 \%$ for cattle farms and $0.37 \%$ for sheep farms. 
Thorn, Green, Dalerum, Bateman, \& Scott

In 2007 the Gross Domestic Product (GDP) of the North West Province was ZAR 129 872 million, of which the agriculture, forestry and fishing industry contributed $2.9 \%$ (Statistics South Africa, 2008). Thus, our extrapolated losses equate to $\leq 0.2 \%$ of 2007 provincial agricultural GDP.

\subsubsection{Perceived culpability of carnivore species}

One hundred and forty nine predation incidents were reported, with varying annual numbers of incidents per farm $\left(25^{\text {th }}\right.$ percentile $=0$, median $=1,75^{\text {th }}$ percentile $\left.=2\right)$. Interviewees attributed $41 \%$ of predation incidents to jackals, $20 \%$ to caracals, $15 \%$ to leopards, $12 \%$ to brown hyaenas, $7 \%$ to cheetahs, $3 \%$ to spotted hyaenas, and only one attack was attributed to servals (Leptailurus serval). Most interviewees (63\%) inferred culpability from spoor and feeding patterns, $21 \%$ witnessed the attacks they reported and $16 \%$ offered no supporting evidence.

\subsubsection{Use of lethal and non-lethal anti-predation measures}

Sixty six of 99 interviewees $(67 \%)$ said that they practiced lethal control of carnivores (Figure 3a). Of the 66 people who used lethal control, 33\% shot carnivores, $20 \%$ used poison, $14 \%$ hunted carnivores at night by playing prey distress calls and then shooting carnivores that responded, 14\% hunted them with dogs and 14\% trapped and then shot them. In the study area, hunting at night or poisoning any wild animal is illegal, and destruction of leopards, cheetahs and brown hyaenas is illegal without a permit. Nonlethal deterrents were used by $63 \%$ of respondents (Figure 3a), the most popular methods being protective enclosures for domestic livestock $(n=30)$, guard dogs $(n=20)$ and human 
guards $(n=17)$. Neither lethal nor non-lethal control methods were used by $16 \%$ of respondents, whereas $32 \%$ used both.

Figure 3. a) The number of interviewees $(n=97)$ who killed carnivores (lethal control) in the year preceding interviews, by cultural group, followed by b) model predictions (see Table $4, \operatorname{Exp}(\hat{\beta}))$ of the effect that financial losses due to carnivore predation have on the odds of carnivore persecution.

(a)

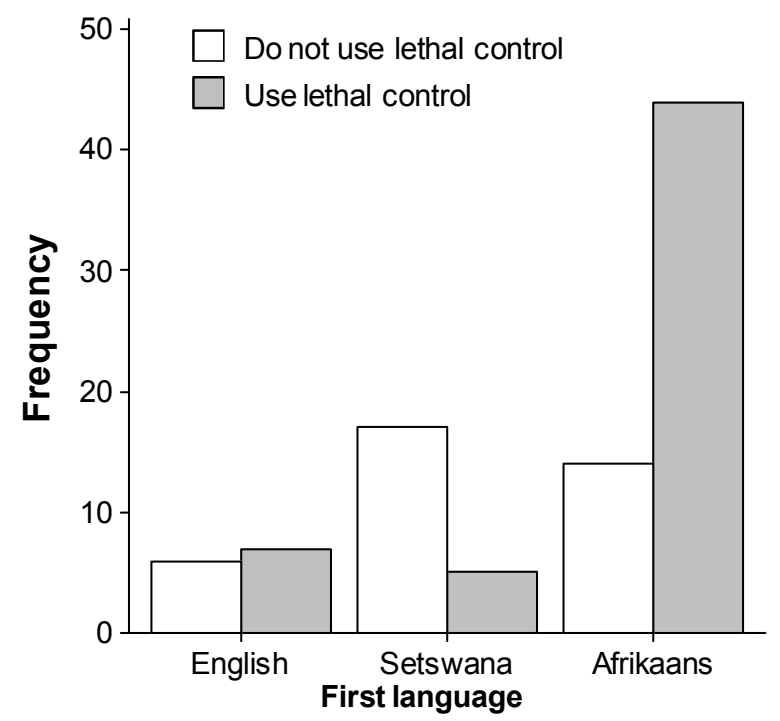

(b)

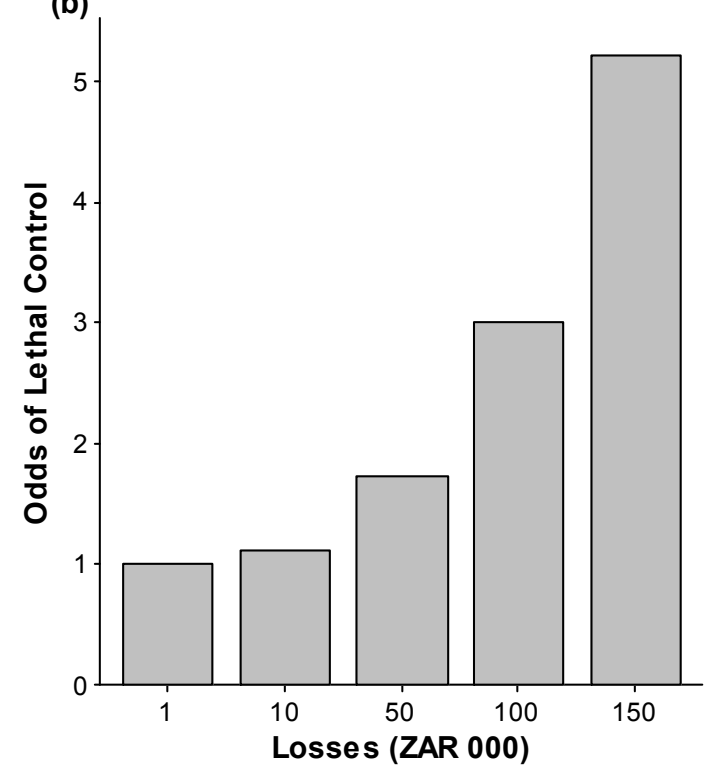

\subsubsection{Number of carnivores killed}

Forty two interviewees reported killing a total of 1216 jackals, 46 caracals, 18 leopards, 9 cheetahs and 3 brown hyaenas in the last year. The number of carnivores killed varied by farm $\left(25^{\text {th }}\right.$ percentile and median $=0,75^{\text {th }}$ percentile $\left.=10\right)$. Overall destruction rates were 29.4 jackals $/ 100 \mathrm{~km}^{2}, 1.1$ caracals $/ 100 \mathrm{~km}^{2}, 0.4$ leopards $/ 100 \mathrm{~km}^{2}, 0.3$ cheetahs $/ 100 \mathrm{~km}^{2}$ and 0.1 brown hyaenas $/ 100 \mathrm{~km}^{2}$ respectively. Estimated annual provincial removals were 18476 jackals, 699 caracals, 275 leopards, 137 cheetahs and 55 brown hyaenas. These 
Thorn, Green, Dalerum, Bateman, \& Scott

figures represent $6 \%$ of estimated leopard numbers in South Africa's 10 main subpopulations (Daly et al., 2005), 34\% of estimated free-ranging cheetah numbers outside of protected areas (Lindsey et al., 2009), and 3\% of estimated total population size for brown hyaenas in South Africa (Mills and Hofer, 1998). There are no current population estimates for jackals and caracals, but both are considered widespread and common (Thorn et al., 2011b).

\subsection{Determinants of predation}

The global additive model showed no evidence of a lack of fit $\left(\chi_{83}^{2}=70.660, \hat{c}=0.851, n\right.$ =94). Nine of the 42 candidate models were within 7 Akaike units of the top ranked model (Table 3). Cover (summed Akaike weight 0.9129) and distance to protected area (summed Akaike weight 0.8473 ) were the most influential variables, followed by land use (summed Akaike weight 0.7566) and anti-predation methods (summed Akaike weight 0.2349). We found no evidence that prey density influenced predation levels (summed Akaike weight 0).

After controlling for the effect of the other variables, the expected predation frequency in farms with predominantly dense cover was 5 times that in farms with open cover (Table 4). The effect of distance to protected area differed with cover categories (Model 9: Table 3), significantly so in farms with predominantly dense cover, where expected predation frequency increased by a factor of 1.022 with distance to protected area (Table 
Thorn, Green, Dalerum, Bateman, \& Scott

Table 3. Generalised linear models that were within $7 \mathrm{AIC}_{\mathrm{c}}$ units of the model with the lowest $\mathrm{AIC}$, with associated degrees of freedom (df), number of parameters in the model $(k), \mathrm{AIC}_{\mathrm{c}}, \Delta \mathrm{AIC}_{\mathrm{c}}$ and $\mathrm{Akaike}$ model weights. DTPA = distance to the nearest protected area.

\begin{tabular}{lrrrrrr}
\hline Model & $\mathrm{df}$ & $k$ & \multicolumn{1}{c}{$\mathrm{AIC}_{\mathrm{c}}$} & $\Delta \mathrm{AIC}_{\mathrm{c}}$ & Weight \\
\hline \multicolumn{4}{l}{ Response variable: no. of game and livestock } & reportedly & killed by carnivores & at each farm \\
1. & Land use + cover + DTPA & 5 & 6 & 694.240 & 0 & 0.5702 \\
2. Anti-predation + cover + DTPA & 6 & 7 & 697.529 & 3.29 & 0.1101 \\
3. Land use + anti-predation + cover & 7 & 8 & 698.183 & 3.94 & 0.0794 \\
4. DTPA + cover & 3 & 4 & 698.716 & 4.48 & 0.0608 \\
5. Land use x DTPA & 3 & 4 & 699.284 & 5.04 & 0.0458 \\
6. Anti-predation + cover & 5 & 6 & 699.611 & 5.37 & 0.0389 \\
7. Land use + DTPA & 3 & 4 & 699.897 & 5.66 & 0.0337 \\
8. Land use + cover & 4 & 5 & 700.714 & 6.47 & 0.0224 \\
9. DTPA x cover & 3 & 4 & 701.015 & 6.78 & 0.0193 \\
Response variable: use (1) or non-use of lethal control $(0)$ & & & \\
1. Culture x age & 3 & 4 & 108.868 & 0 & 0.4764 \\
2. Culture + ZAR losses & 3 & 4 & 109.260 & 0.39 & 0.3916 \\
3. Culture & 2 & 3 & 111.437 & 2.57 & 0.1319 \\
\hline
\end{tabular}

4, Figure 2d). Expected predation frequency in livestock farms increased by a factor of 1.008 with every additional $\mathrm{km}$ from a protected area (Model 5: Table 3, Table 4).

Expected predation frequency in game and mixed farms was 1.031 and 1.033 higher respectively, but also increased with distance from protected areas (Table 4, Figure 2c). Expected predation frequency was greatest in farms using both lethal and non-lethal antipredation measures, lower in farms using of non-lethal anti-predation methods, still lower in farms that use lethal control, and lowest in farms that use neither (Table 4).

\subsection{Determinants of lethal control}

There was no evidence of a lack of fit in the global additive model $\left(\chi_{89}^{2}=92.88, \hat{c}=1.04\right.$, $n=96$ ). Three of the 27 candidate models were within 7 Akaike units of the top ranked model (Table 3). Cultural group was by far the most influential determinant (summed 
Thorn, Green, Dalerum, Bateman, \& Scott

Akaike weight 1), followed by land owner age (summed Akaike weight 0.4765 ) and financial losses (summed Akaike weight 0.3917). We found no evidence that land use influenced use of lethal control (summed Akaike weight 0).

Table 4. Estimated regression coefficients $(\hat{\beta})$, standard errors $( \pm \mathrm{SE})$ and odds ratios from generalised linear models that were within $7 \mathrm{AIC}_{\mathrm{c}}$ units of the model with the lowest $\mathrm{AIC}_{\mathrm{c}}$. Bold $\hat{\beta}$ values differed significantly from zero and ' $*$ ' indicates near-significant values. DTPA denotes the variable 'distance to the nearest protected area'.

\begin{tabular}{lccr}
\hline Parameter & $\hat{\beta}$ & $\pm \mathrm{SE}(\hat{\beta})$ & $\mathrm{Exp}(\hat{\beta})$ \\
\hline Response variable: no. of game and livestock reportedly killed by carnivores at each farm Reference \\
categories: cover = open, land use = livestock, anti-predation = both & & & \\
(Land use = mixed) x DTPA (model 5) & $\mathbf{0 . 0 3 2}$ & 0.0077 & 1.033 \\
(Land use = game) x DTPA (model 5) & $\mathbf{0 . 0 3 1}$ & 0.0116 & 1.031 \\
(Land use = livestock) x DTPA (model 5) & $\mathbf{0 . 0 0 8}$ & 0.0039 & 1.008 \\
(Cover = open) x DTPA (model 9) & -0.010 & 0.0054 & 0.990 \\
(Cover = heterogeneous) x DTPA (model 9) & 0.007 & 0.0095 & 1.007 \\
(Cover = dense) x DTPA (model 9) & $\mathbf{0 . 0 2 2}$ & 0.0061 & 1.022 \\
Cover = dense (model average) & $\mathbf{1 . 6 6 4}$ & 0.5029 & 5.279 \\
Cover = heterogeneous (model average) & 0.773 & 0.4795 & 2.167 \\
Distance to protected area (model average) & $\mathbf{0 . 0 1 0}$ & 0.0046 & 1.010 \\
Land use = game (model average) & $\mathbf{0 . 7 4 6}$ & 0.4087 & 2.108 \\
Land use = mixed (model average) & $\mathbf{0 . 9 2 1}$ & 0.3878 & 2.512 \\
Anti-predation = non lethal (model average) & -0.042 & 0.1393 & 0.959 \\
Anti-predation = neither (model average) & -0.340 & 0.2830 & 0.711 \\
Anti-predation = lethal (model average) & -0.008 & 0.1022 & 0.992 \\
& & & \\
Response variable: use (1) or non-use of lethal control (0) & & & \\
Reference category: Culture = Setswana-speaking & & & \\
Afrikaans-speaking x age (model 1) & 0.033 & 0.0233 & 1.034 \\
English-speaking x age (model 1) & 0.013 & 0.0276 & 1.013 \\
Setswana-speaking x age (model 1) & -0.032 & 0.0233 & 0.969 \\
Afrikaans-speaking (model average) & $\mathbf{2 . 9 4 1}$ & 0.7270 & 18.929 \\
English-speaking (model average) & $\mathbf{1 . 8 9 5}$ & 0.8050 & 6.653 \\
ZAR losses (000) (model 2) & $* 0.011$ & 0.0055 & 1.011 \\
\hline
\end{tabular}


Thorn, Green, Dalerum, Bateman, \& Scott

After controlling for the effect of other variables, the odds of lethal control were about 19 times greater among Afrikaans-speaking farmers and about 7 times greater among English-speaking farmers, compared to Setswana-speaking farmers (Table 4). The odds of lethal control increased by a factor of 1.011 with every additional ZAR 1000 financial loss (Table 4, Figure 3b).

\section{Discussion}

\subsection{Characteristics of human-carnivore conflict}

In other recent African studies Namibian farmers reportedly lost $1.4 \%$ of total stock holdings to large carnivores (Marker et al., 2003), compared with 1.8\% in Kenya (Kolowski and Holekamp, 2006), 2.2\% in Botswana (Schiess-Meier et al., 2007) and $4.5 \%$ in Tanzania (Holmerna et al., 2007). Our perceived annual predation rate of $2.77 \%$ of total stock holdings does not therefore seem excessive, particularly as many respondents reported below-average annual rainfall during the study period. In areas where prey abundance peaks in the wet season (as in our study area), low rainfall is thought to reduce natural prey biomass, leading to increased livestock predation (Kolowski and Holekamp, 2006).

Perceived financial losses $\leq$ ZAR $1.23 /$ ha/year are unlikely to pose a serious threat to commercial farming livelihoods in general, particularly as $62 \%$ of farmers considered predation less costly than poaching and drought. However, farmers who believe that destruction of carnivores is effective may consider poaching and drought more difficult and costly to mitigate. Furthermore, predation undoubtedly constitutes a grave financial 
Thorn, Green, Dalerum, Bateman, \& Scott

concern for the small proportion of farmers with losses at the high end of the scale. Game farms that stock high value ungulates are vulnerable to disproportionately high financial losses from relatively low predation frequencies.

At $\leq 0.2 \%$ of provincial agricultural GDP, the estimated provincial economic effect of predation appears negligible. However, the agricultural sector in South Africa has indirect links to many other industries, is a major provider of employment in rural areas and is a significant source of foreign exchange (Department of Agriculture Forestry and Fisheries, 2010). Therefore, the absolute value of agricultural GDP does not necessarily reflect the overall economic importance of the sector.

Our results suggest preferential predation on relatively abundant small to medium-sized animals (Table 2), which corresponds with the results of dietary studies (Hayward et al., 2006a; Hayward et al., 2006b; Mills and Mills, 1978; van der Merwe et al., 2009). Such apparent preferences would also explain why young domestic livestock were preyed upon more often than larger adult animals. The majority of perceived predation incidents were attributed to jackals and caracals. Both species are widespread and abundant (Thorn et al., 2011b), despite extremely high persecution rates. Historical records and recent survey data suggest that this is due to meso-predator release (see Thorn et al., 2011b and references therein). This phenomenon is characterised by increased abundance or distribution of middle-ranked predators, caused by declining density or distribution of larger, socially dominant predators (Prugh et al., 2009). A lack of top-down regulation by apex carnivores (resident only in reserves) would also explain the positive relationship 
Thorn, Green, Dalerum, Bateman, \& Scott

between predation (mainly perpetrated by meso-carnivores) and distance to protected areas. This pattern is atypical of other African areas (but see Gusset et al., 2009), possibly because most studies focussed on relatively undeveloped agricultural areas and sites near un-fenced reserves containing apex predators.

It appears that jackal and caracal conservation status in the study area is largely unaffected by human-carnivore conflict. However, as jackals and caracals do not have individually distinct markings, it is rarely possible to identify and selectively remove ‘problem animals'. Incidentally killing large numbers of non-damage-causing individuals may be ethically unsound and reduces the ecological benefits conferred by these species (e.g. regulation of rodent populations) (Prugh et al., 2009). Killing them in such a way may alternatively be considered an attempt to reduce their densities to the levels expected if apex predators were present. However, grazing management, rather than lethal control, is the main driver of long term jackal and caracal abundance in South African rangelands (Blaum et al., 2009). Studies of other meso-carnivores such as red foxes (Baker and Harris, 2006) and coyotes (Sterling et al., 1983), suggest that lethal control has little long term benefit because heavy culling triggers compensatory demographic responses such as increased immigration and recruitment, and reduced emigration and natural mortality (Baker and Harris, 2006; Prugh et al., 2009; Sterling et al., 1983). This may cause high population turnover and actual or perceived population growth (Prugh et al., 2009), potentially escalating human-meso-predator conflict and decreasing tolerance toward all carnivores. Marker et al. (2003) made similar suggestions after detecting a strong relationship between perceived jackal and cheetah 
Thorn, Green, Dalerum, Bateman, \& Scott

problems. Resolving human-meso-predator conflict may therefore be important in reducing persecution-related threats to more vulnerable carnivore species.

The effect that reported destruction rates have on the conservation status and sustainability of the other focal species is difficult to infer because of a lack of reliable, contemporary population estimates and local demographic data. However, brown hyaenas occur within a restricted distribution range in the South West Arid Zone of Southern Africa and the estimated global population comprises $<10,000$ mature individuals (Wiesel et al., 2008). A 10\% population decline over three generations would cause brown hyaenas to be re-classified as Vulnerable (Wiesel et al., 2008). Therefore, an annual provincial destruction rate of $3 \%$ of the national population could constitute a serious threat to the species.

The South African cheetah population is globally important because it forms part of the largest remaining population in southern Africa (Lindsey et al., 2009). Outside of protected areas, cheetah range in South Africa is restricted to a narrow belt along the northern border of the country, with the North West Province roughly in the middle (Marnewick et al., 2007b; Thorn et al., 2011b). A large provincial population decline (e.g. $34 \%$ of the national population) could therefore create a significant population sink, threatening wider national and regional metapopulation viability (Lindsey et al., 2009). 
Thorn, Green, Dalerum, Bateman, \& Scott

\subsection{Determinants of human-carnivore conflict}

In general, our results suggest that any conflict mitigation activities aimed at reducing predation levels should focus on mixed and game farms, those with predominantly dense cover, and those furthest from protected areas. Elevated predation pressure in farms with dense cover probably stems from reduced visibility of approaching predators, increasing hunting success. Furthermore, the woodland and scrub habitats included in the 'dense cover' category are often associated with natural succession in farms that have converted from intensive grazing to game farming (Hejcmanova et al., 2010). Natural succession is likely to result in generally increased biodiversity and improved ecological function (e.g. reduced soil erosion and improved nutrient cycling). Game farms may therefore support greater carnivore densities, and provide refuge from human disturbance and persecution, leading to co-incidentally high predation levels.

Although it may be advisable to remove cover in close proximity to livestock enclosures (Woodroffe et al., 2007), reducing cover throughout game farms would counteract the benefits of natural succession. Options for reducing predation costs in game farms are therefore likely to rely on measures that prevent carnivores from entering, effectively control problem carnivore abundance (Woodroffe and Frank, 2005), or increase the relative abundance of the least expensive small-medium sized prey species (Inskip and Zimmermann, 2009). The latter may be especially important in tribal areas of the province, where aerial surveys suggest that free-ranging ungulate densities are particularly low (personal communication, North West Department of Agriculture, Conservation and Environment, 2009). This approach should be generally acceptable as 
Thorn, Green, Dalerum, Bateman, \& Scott

it appears land owners are already implementing anti-predation measures in ascending order of severity as predation pressure increases (neither lethal nor non-lethal methods, then non-lethal methods, lethal and finally, both lethal and non-lethal methods). In view of this, the fact that $67 \%$ of interviewees practice lethal control indicates that predation pressure is widely perceived to be high.

As in our study, Lindsey et al. (2005) reported that Afrikaans-speaking farmers and older people were less tolerant of carnivores. Conflict mitigation strategies aimed at increasing tolerance of carnivores should therefore focus on older Afrikaans and English speakers and young Setswana-speaking farmers. Activities aimed at maintaining positive attitudes to carnivores may prove more productive and should focus on young Afrikaans or English-speaking farmers and older Setswana speakers. Based on summed Akaike weights, activities aimed at reducing financial loss are likely to be less advantageous. However, they may play a role in improving attitudes and fostering good relations between conservationists and farmers. Where attempted, our study indicates that such activities should entail increased protection of young animals, high-value antelope, and relatively abundant species with body weight $\leq 70 \mathrm{~kg}$. It may also be helpful to measure the relationship between actual and perceived losses, or the number of predated animals that were terminally afflicted with disease, delivery complications, old age or wounds.

\section{Conclusions}

Conflict in the North West Province appears to be driven more by social and environmental factors than by perceived financial losses, which appear to have limited 
Thorn, Green, Dalerum, Bateman, \& Scott

economic impact. However, in view of the complex linkages between agriculture and other sectors, further research will be needed to confirm the wider economic importance of predation. In particular, direct and indirect effects of conflict in subsistence farming areas require clarification. Similarly, the cost of carnivore predation should be compared with the value that large carnivores add in terms functional benefits, eco-tourism, and hunting income.

Apart from Blaum et al. (2009), there is limited information available regarding the effects of human persecution (and other sources of mortality) on jackal and caracal abundance, demography, and predation rates in South Africa. We suggest this as a topic for urgent empirical investigation in view of the perceived impact that these species have in farmland, and the adverse effect that human-meso-predator conflict may have on other, more vulnerable carnivores. Current levels of brown hyaena and cheetah persecution may pose a serious threat to local and regional populations, particularly as our rates do not account for additional removals due to factors such as road kills, natural mortality, or illegal trade. In view of this, additional efforts to quantify illegal removals are imperative, and large-scale monitoring of either distribution or abundance would be advisable. Indeed, additional research is required to improve our understanding of population size, demographic rates and meta-population function for all of the focal carnivore species, both locally and nationally.

In order to guide the selection of appropriate conflict mitigation activities and optimise their success, it would be useful to investigate why the use of lethal control varies with 
Thorn, Green, Dalerum, Bateman, \& Scott

social factors (cultural group and age). It would also be helpful to evaluate temporal trends in predation as this may elucidate seasonal variation in the cost and benefit of antipredation methods. In-situ empirical testing of non-lethal anti-predation methods is also recommended, given the general shortage of empirical data concerning their effectiveness (Inskip and Zimmermann, 2009).

Finally, it is important to acknowledge that data from interviews comprise reported information, some of which may be subject to bias. Nevertheless, quantitative information about human-carnivore conflict in South Africa is scant so our findings represent an important first step toward the development of effective, context-specific conflict-mitigation strategies. More widely, our combination of socio-economic interviews and information theoretic analysis demonstrates a simple and effective method for extricating the key determinants of other complex human-wildlife conflicts.

\section{ACKNOWLEDGEMENTS}

We thank the tribal authorities who allowed us to survey on their land and are enormously grateful to all of the people who provided information during interviews. We are also indebted to G. Gaboinewe and G. S. Molale who helped administer questionnaires, and to K. Marnewick and D. Cilliers for initial introductions to landowners. We thank anonymous reviewers for their comments, which greatly improved the manuscript. We are also grateful to S. Uzzell for providing computer equipment, the University of Brighton, U.K. and the Leverhulme Trust U.K. for funding, and the Earthwatch Institute for their support. 
Thorn, Green, Dalerum, Bateman, \& Scott

\section{LITERATURE CITED}

ABSA, 2003. Game ranch profitability in Southern Africa. Third edition. ABSA Group:

The finanical sector forum, Johannesburg.

Baker, P.J., Harris, S., 2006. Does culling reduce fox (Vulpes vulpes) density in commercial forests in Wales, UK? European Journal of Wildlife Research 52, 99108.

Blaum, N., Tietjen, B., Rossmanith, E., 2009. Impact of livestock husbandry on smalland medium-sized carnivores in Kalahari savannah rangelands. Journal of Wildlife Management 73, 60-67.

Bothma, J.d.P., 2005. Extensive Wildlife Production in South Africa. Keynote address: Wildlife Seminar, Northern Game Farmers' Organisation, Pretoria, 11 March 2005.

Burnham, K.P., Anderson, D.R., 2002. Model selection and multimodel inference: a practical information-theoretic approach, second edn. Springer-Verlag, New York.

Burnham, K.P., Anderson, D.R., Huyvaert, K.P., 2011. AIC model selection and multimodel inference in behavioral ecology: some background, observations, and comparisons. Behavioral Ecology and Sociobiology 65, 23-35.

Cook, R.D., Weisberg, S., 1982. Residuals and influence in regression. Chapman \& Hall, New York.

Daly, B., Power, J., Camancho, G., Traylor-Holtzer, K., Barber, S., Caterrall, S., Fletcher, P., Martins, Q., Martins, N., Owen, C., Tahl, T., Freidmann, Y. eds., 2005. Leopard (Panthera pardus) population habitat viability assessment workshop 
Thorn, Green, Dalerum, Bateman, \& Scott

report. Conservation Breeding Specialist Group (SCC/IUCN) / CSBG Southern Africa \& The Endangered Wildlife Trust.

Dar, N.I., Minhas, R.A., Zaman, Q., Linkie, M., 2009. Predicting the patterns, perceptions and causes of human-carnivore conflict in and around Machiara National Park, Pakistan. Biological Conservation 142, 2076-2082.

De Villiers, B., Mangold, S., 2002. Chapter 2: the biophysical environment, In North West Province State of the Environment Report. eds D. Walmsley, J. Walmsley, S. Mangold, M. Kalule-Sabiti. Directorate of Environment and Conservation Management. North West Department of Agriculture, Conservation and Environment, Mmabatho.

Department of Agriculture Forestry and Fisheries, 2010. Abstract of agricultural statistics. Department of agriculture, forestry and fisheries, South Africa, Pretoria.

Friedmann, Y., Daly, D. eds., 2004. Red data book of the mammals of South Africa: a conservation assessment. CBSG Southern Africa, Conservation Breeding Specialist Group (SSC/IUCN) \& The Endangered Wildlife Trust, Johannesburg.

Graham, K., Beckerman, A.P., Thirgood, S., 2005. Human-predator-prey conflicts: ecological correlates, prey losses and patterns of management. Biological Conservation 122, 159-171.

Gusset, M., Swarner, M.J., Mponwane, L., Keletile, K., McNutt, J.W., 2009. Humanwildlife conflict in northern Botswana: livestock predation by endangered African wild dog Lycaon pictus and other carnivores. Oryx 43, 67-72. 
Thorn, Green, Dalerum, Bateman, \& Scott

Hayward, M.W., Henschel, P., O'Brien, J., Hofmeyr, M., Balme, G., Kerley, G.I.H., 2006a. Prey preferences of the leopard (Panthera pardus). Journal of Zoology 270, 298-313.

Hayward, M.W., Hofmeyr, M., O'Brien, J., Kerley, G.I.H., 2006b. Prey preferences of the cheetah (Acinonyx jubatus) (Felidae: Carnivora): morphological limitations or the need to capture rapidly consumable prey before kleptoparasites arrive? Journal of Zoology 270, 615-627.

Hejcmanova, P., Hejcman, M., Camara, A.A., Antoninova, M., 2010. Exclusion of livestock grazing and wood collection in dryland savannah: an effect on long-term vegetation succession. African Journal of Ecology 48, 408-417.

Holmerna, T., Nyahongoa, J., Røskafta, E., 2007. Livestock loss caused by predators outside the Serengeti National Park, Tanzania. Biological Conservation 135, 518 526.

Inskip, C., Zimmermann, A., 2009. Human-felid conflict: a review of patterns and priorities worldwide. Oryx 43, 18-34.

IUCN, 2009. Table 4a: red list category summary for all animal classes and orders, In IUCN 2009 Red List of Threatened Species. www.iucnredlist.org.

Jacobs, J., 1974. Quantitative measurement of food selection - a modification of the forage ratio and Ivlev's electivity index Oecologia 14, 413-417.

Kolowski, J.M., Holekamp, K.E., 2006. Spatial, temporal, and physical characteristics of livestock depredations by large carnivores along a Kenyan reserve border. Biological Conservation 128, 529-541. 
Thorn, Green, Dalerum, Bateman, \& Scott

Lindsey, P., Marnewick, K., Davies-Mostert, H., Rehse, T., Mills, M.G.L., Brummer, R., Buk, K., Traylor-Holtzer, K., Morrison, K., Mentzel, C., Daly, B. eds., 2009. Cheetah (Acinonyx jubatus) population habitat viability assessment workshop report. Conservation Breeding Specialist Group (SCC/IUCN) / CSBG Southern Africa \& The Endangered Wildlife Trust.

Lindsey, P.A., du Toit, J.T., Mills, M.G.L., 2005. Attitudes of ranchers towards African wild dogs Lycaon pictus: conservation implications on private land. Biological Conservation $125,113-121$.

Marker, L.L., Mills, M.G.L., Macdonald, D.W., 2003. Factors influencing perceptions of conflict and tolerance towards cheetahs on Namibian farmlands. Conservation Biology 17, 1290-1298.

Marnewick, K.c., Beckhelling, A., Cilliers, D., Lane, E., Mills, G., Herring, K., Caldwell, P., Hall, R., Meintjes, S.c., 2007a. The Status of the Cheetah in South Africa. Cat News Special Issue 3 - Cheetahs in Southern Africa, 22-31.

Marnewick, K.c., Beckhelling, A., Cilliers, D., Lane, E., Mills, G., Herring, K., Caldwell, P., Hall, R., Meintjes, S.c., 2007b. The Status of the Cheetah in South Africa. Cat News Special issue 3, 22-31.

Michalski, F., Boulhosa, R.L.P., Faria, A., Peres, C.A., 2006. Human-wildlife conflicts in a fragmented Amazonian forest landscape: determinants of large felid depredation on livestock. Animal Conservation 9, 179-188.

Mills, M.G.L., Hofer, H. eds., 1998. Hyaenas. Status survey and conservation action plan. IUCN/SSC Hyaena Specialist Group. IUCN, Gland and Cambridge. 
Thorn, Green, Dalerum, Bateman, \& Scott

Mills, M.G.L., Mills, M.E.J., 1978. The diet of the brown hyaena (Hyaena brunnea) in the southern Kalahari. Koedoe 21, 125-150.

Molewa, B.E.E., 2010. National Environmental Management: Biodiversity Act, 2004:

Act 10 of 2004. Draft Norms and Standards for the Managment of DamageCausing Animals in South Africa, ed. D.o.e. affairs. Government Gazette 33806, Cape Town.

Murray, D.L., Kapke, C.A., Evermann, J.A., Fuller, T.K., 1999. Infectious disease and the conservation of free-ranging large carnivores. Animal Conservation 2, 241254.

Prugh, L.R., Stoner, C.J., Epps, C.W., Bean, W.T., Ripple, W.J., Laliberte, A.S., Brashares, J.S., 2009. The rise of the mesopredator. Bioscience 59, 779-791.

Schiess-Meier, M., Ramsauer, S., Gabanapelo, T., Koenig, B., 2007. Livestock predation - Insights from problem animal control registers in Botswana. Journal of Wildlife Management 71, 1267-1274.

Statistics South Africa, 2007. Census of Commercial Agriculture 2007, Statistical release P1101. Statistics South Africa, Pretoria.

Statistics South Africa, 2008. Gross Domestic Product: Annual estimates per region 1995 - 2007. Fourth quarter: 2008, Statistical release P0441. Statistics South Africa, Pretoria.

Sterling, B., Conley, W., Conley, M.R., 1983. Simulations of demographic compensation in coyote populations. Journal of Wildlife Management 47, 1177-1181.

Thorn, M., Green, M., Bateman, P., Waite, S., Scott, D., 2011a. Brown hyaenas on roads: Landscape-scale estimation of carnivore occupancy and population size from 
Thorn, Green, Dalerum, Bateman, \& Scott

spatially auto-correlated sign surveys replicates. Biological Conservation 144, 1799-1807.

Thorn, M., Green, M., Keith, M., Marnewick, K., Bateman, P., Cameron, E.Z., Scott, D., 2011b. Large-scale distribution patterns of carnivores in northern South Africa: implications for conservation and monitoring. Oryx 45, 579-586.

Tladi, B., Baloyi, T., Marfo, C., 2002. Chapter 6: settlement and land use patterns, In North West Province State of the Environment Report eds D. Walmsley, J. Walmsley, S. Mangold, M. Kalule-Sabiti. Directorate of Environment and Conservation Management. North West Department of Agriculture, Conservation and Environment, Mmabatho.

Treves, A., Karanth, K.U., 2003. Human-carnivore conflict and perspectives on carnivore management worldwide. Conservation Biology 17, 1491-1499.

van der Merwe, I., Tambling, C.J., Thorn, M., Scott, D., Yarnell, R., Green, M., Cameron, E.Z., Bateman, P.W., 2009. An assessment of diet overlap of two mesocarnivores in the North West Province, South Africa. African Zoology 44, 288-291.

Wiesel, I., Maude, G., Scott, D., Mills, G., 2008. Hyaena brunnea, In 2008 IUCN Red List of Threatened Species. www.iucnredlist.org.

Woodroffe, R., Frank, L.G., 2005. Lethal control of African lions (Panthera leo): local and regional population impacts. Animal Conservation 8, 91-98.

Woodroffe, R., Frank, L.G., Lindsey, P.A., Ranah, S., Romanach, S., 2007. Livestock husbandry as a tool for carnivore conservation in Africa's community rangelands: a case-control study. Biodiversity and Conservation 16, 1245-1260. 